05

\title{
Экспериментальное и теоретическое исследование высокоскоростного проникания длинных стержневых ударников в песок
}

\author{
(С) С.И. Герасимов, ${ }^{1,2}$ Ю.Ф. Травов, ${ }^{1}$ А.Г. Иоилев, ${ }^{1,2}$ В.В. Писецкий, ${ }^{2}$ Н.Н. Травова, ${ }^{2}$ А.П. Калмыков, ${ }^{1}$ \\ C.А. Капинос, ${ }^{1}$ Н.В. Лапичев, ${ }^{1}$ Ю.И. Файков ${ }^{1}$ \\ ${ }^{1}$ Российский фредеральный ядерный центр Всероссийский научно-исследовательский \\ институт экспериментальной физики, \\ 607188 Саров, Россия \\ ${ }^{2}$ Саровский физико-технический институт - Национальный исследовательский ядерный университет „МИФИ“, \\ 607184 Саров, Россия \\ e-mail: SIGerasimov@vniief.ru, YFTravov@vniief.ru
}

Поступило в Редакцию 13 октября 2021 г.

В окончательной редакции 12 декабря 2021 г.

Принято к публикации 13 декабря 2021 г.

\begin{abstract}
Представлено сопоставление результатов расчетов по усовершенствованной модифицированной гидродинамической теории Алексеевского-Тейта (УМГТ) с опытными данными по высокоскоростному прониканию (скорость удара в диапазоне $V_{0}=0.5-3.5 \mathrm{~km} / \mathrm{s}$ ) в песок длинных стержневых ударников из трех разных металлов: меди М1, вольфрамового сплава ВНЖ и стали 30ХГСА. Показано, что с помощью УМГТ и с использованием экспериментальных данных по зависимости коэффициента относительного проникания $K$ от скорости внедрения можно определить коэффициент упрочнения $k$ в линейной зависимости предела текучести материала ударника от давления. Показано, что при проникании в режиме гидродинамического срабатывания ударника коэффициент относительного проникания $K$ может быть аппроксимирован зависимостью только от отношения начальной скорости внедрения к критической скорости, при превышении которой проникание происходит с пластическим деформированием ударника. Значение критической скорости для конкретных свойств материала ударника и плотности и влажности песка может отличаться.
\end{abstract}

Ключевые слова: высокоскоростное проникание, пластическое деформирование, предел текучести, гидродинамическое срабатывание, теория Алексеевского-Тейта, эксперимент.

DOI: $10.21883 /$ JTF.2022.03.52134.275-21

\section{Введение}

Для описания процесса высокоскоростного проникания цилиндрического ударника (стержня) в песчаный грунт в модифицированную гидродинамическую теорию (МГТ) Алексеевского-Тейта [1-3] было введено усовершенствование [4], которое позволяет рассчитать процесс высокоскоростного проникания ударников в малопрочную преграду как в гидродинамической, так и пластической стадиях деформирования. В усовершенствованной МГТ (УМГТ) используются следующие экспериментальные данные:

- критическая скорость $V^{*}$ (скорость внедрения, при которой начинается пластическая стадия проникания для конкретных параметров грунта);

- коэффициент давления в точке торможения $\bar{P}_{T}$;

- скорость распространения пластической волны в стержне $C_{p}$;

- зависимость предела текучести материала ударника от давления $Y_{p}(P)$.

В работе [4] УМГТ применена для описания экспериментальных данных по высокоскоростному прониканию стержней из меди М1 в песок. В настоящей работе в рассмотрение включено также проникание в песчаный грунт стержней из сплава ВНЖ [5] и стали 30ХГСА.

\section{1. Физическая схема деформирования стержней при высокоскоростном внедрении в малопрочные преграды}

При высокоскоростном проникании ударников в плотные среды различают три режима их деформирования, которые реализуются при различной скорости движения [6-8]:

1) режим „твердого тела“ - ударник деформируется упруго;

2) режим пластического деформирования - уменьшение длины ударника происходит с постоянной скоростью, равной скорости продольной пластической волны $C_{p}$;

3) режим гидродинамического срабатывания - скорость срабатывания ударника $V-U$ превышает скорость продольной пластической волны $(V-$ скорость хвостовой недеформированной части ударника; $U-$ скорость проникания). 

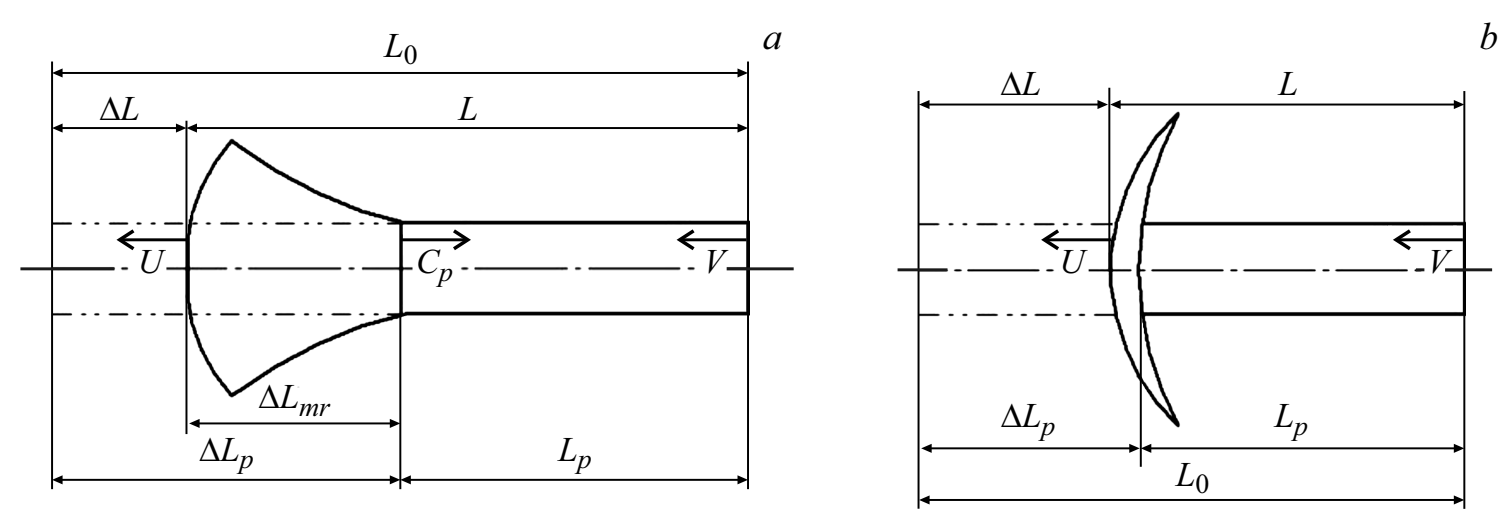

Рис. 1. Схема деформирования ударника при высокоскоростном проникании в песок: $a-$ режим пластического деформирования, $b-$ режим гидродинамического срабатывания $\left(\Delta L_{p}=\Delta L\right)$.

На рис. 1 приведены схемы деформирования цилиндрического ударника, соответствующие пластическому и гидродинамическому режимам. Размеры $L$ и $L_{p}$ определяются по рентгеновскому снимку ударника в грунте на фиксированный момент внедрения [9].

На рис. 1 , а $\Delta L_{m r}$ - размер пластически деформированной передней части. Заметим, что пластически деформированная передняя часть ударника четко различима только у ударников из пластичных материалов. В случае же ударников из хрупких материалов (высокопрочные стали, керамические соединения, карбид вольфрама и пр.) пластически деформированная передняя часть может разрушаться на обломки, которые уносятся в радиальном направлении материалом преграды.

Если при пластическом режиме текущая длина ударника $L$ будет равна его длине после полного торможения в преграде, то это означает, что, по крайней мере с момента рентгенографирования и до остановки, проникание происходило в режиме „твердого тела“, но форма этого тела - не начальная, а пластически деформированная на момент времени рентгенографирования.

Проникание ударника проходит при пластическом режиме деформирования, если скорость внедрения превышает некоторое критическое значение $V_{*}$, которое можно оценить с помощью модифицированного уравнения Бернулли [1,2], выражающего равенство давлений в критической точке со стороны грунта и со стороны стержня:

$$
\frac{1}{2} \rho_{p}(V-U)^{2}+Y_{p}=\frac{1}{2} \bar{P}_{T} \rho_{t} U^{2}+R_{t}
$$

где $\rho_{p}$ и $\rho_{t}-$ плотность металлического стержня (проникателя) и преграды (мишени), $Y_{p}$ - динамический предел текучести материала проникателя, $R_{t}$ - динамическая твердость материала преграды. Если преграда мягкий грунт, то материал ударника прочнее материала преграды $R_{t} \ll Y_{p}$, так что в дальнейшем значением $R_{t}$ по сравнению с $Y_{p}$ будем пренебрегать. Для учета существенной сжимаемости грунтовой преграды в уравнение (1) введен коэффициент давления $\bar{P}_{T}$.
Переходу от режима проникания ударника как „твердого тела“ к режиму проникания ударника с его пластическим деформированием соответствует условие $V=U=V_{*}$, т. е. критическая скорость проникания равна

$$
V_{*}^{2}=2 \frac{\left(Y_{*}-R_{t}\right)}{\rho_{t} \bar{P}_{T}}
$$

В классической МГТ (см., например, $[3,6]) Y_{p}-$ это постоянная динамическая прочность ударника, обозначающая напряжение, при превышении которого материал ударника становится „жидким“. В уравнении (1) динамический предел текучести материала ударника $Y_{p}$ считается зависящим от давления (скорости) [4], в соотношении (2) $Y_{*}$ - предел текучести при критической скорости $V_{*}$.

Величина $\bar{P}_{T}$ близка к коэффициенту сопротивления $C_{x}$ плоского торца цилиндра. При использовании непосредственно экспериментального значения $C_{x}$ (с учетом его зависимости от влажности грунта [10]) нет необходимости учитывать $R_{t}$, так как оно уже учтено в полном коэффициенте сопротивления.

Проникание происходит в гидродинамическом режиме [6], если скорость проникания превышает скорость гидродинамического перехода $V_{h t}$, которая определяется из уравнения (1), при условии: скорость срабатывания ударника $(V-U)$ равна скорости продольной пластической волны $C_{p}$.

Если продольное напряжение $\sigma_{x}<50 \mathrm{GPa},{ }^{1}$ когда влияние температуры еще не существенно, то предел текучести металла можно считать линейно зависящим от реализующегося давления $[11,12]$ :

$$
Y_{p}(P)=Y_{0}+k P,
$$

где $k-$ коэффициент упрочнения. Давление в критической точке ударника $P$ можно оценить как $P=C_{x} \rho_{t} V^{2} / 2$.

\footnotetext{
${ }^{1}$ Во всех представленных в настоящей работе опытах давление, возникающее при проникании ударников в песчаный грунт, не превышает $\approx 25 \mathrm{GPa}$.
} 
Тогда из соотношения (2) (при $Y_{p}>Y_{*}$ ) следует, что $P_{*}=Y_{*}$ и, следовательно, $Y_{*}=Y_{0}+k Y_{*}$, и выражение (3) можно записать как

$$
Y_{p}(P)=Y_{*}(1-k)+k P .
$$

Тогда скорость гидродинамического перехода определяется из (1) как

$$
V_{h t}=\frac{C_{p}}{1-k}+\left[V_{*}^{2}+\frac{C_{p}^{2}}{(1-k)^{2}}\left(k+\frac{1-k}{C_{x} \mu^{2}}\right)\right]^{1 / 2},
$$

где $\mu=\sqrt{\rho_{t} / \rho_{p}}$.

При постоянном пределе текучести $k=0$ выражение для скорости гидродинамического перехода упрощается:

$$
V_{h t}=C_{p}+\left[V_{*}^{2}+\frac{1}{C_{x}}\left(\frac{C_{p}}{\mu}\right)^{2}\right]^{1 / 2} .
$$

Практический интерес представляют еще две характерные скорости внедрения в малопрочные преграды $V_{p}$ и $V_{s h t}$, которые можно вычислить расчетом по УМГТ.

Скорость $V_{s h t}$ - это минимальная скорость внедрения в гидродинамическом режиме $\left(V_{s h t}>V_{h t}\right)$, при которой происходит полное гидродинамическое срабатывание ударника к моменту торможения его до скорости гидродинамического перехода $V_{h t}$.

Скорость $V_{p}$ - это минимальная скорость внедрения, при которой ударник полностью пластически деформируется, т.е. либо полностью сожмется до длины $L=\Delta L_{m r}$, достигнув при торможении критической скорости $V_{*}$ (случай „мягкого“ металла в пластической стадии деформирования), либо полностью разрушится (случай хрупкого металла).

При скорости внедрения $V_{0}<V_{p}$ всегда остается твердый остаток ударника, который продолжает движение в режиме „твердого тела“. Данный режим проникания в настоящей работе не рассматривается. Скорость $V_{p}$ может быть как меньше скорости гидродинамического перехода $V_{h t}$, так и больше. В последнем случае при скорости удара $V_{p}>V_{0}>V_{h t}$ проникание сначала проходит в режиме гидродинамического срабатывания ударника, затем - в режиме его пластического деформирования и, наконец, в режиме „твердого тела“. Ситуация, когда $V_{p}>V_{h t}$, имеет место в случае относительно небольшого отличия критической скорости $V_{*}$ от скорости гидродинамического перехода $V_{h t}$, что, в свою очередь, определяется скоростью пластической волны $C_{p}$ и достаточно высоким значением $V_{*}$.

Одним из основных параметров, характеризующих высокоскоростное взаимодействие ударника с преградой, является коэффициент относительного проникания $K=h / \Delta L \quad(h-$ текущая глубина внедрения; $\Delta L-$ укорочение (срабатывание) ударника). Коэффициент $K$ позволяет предсказать полную глубину срабатывания ударника при проникании в гидродинамическом режиме. Согласно схеме Алексеевского-Тейта [1,2], величина $K$ зависит от скорости внедрения $V$. При увеличении $V$ значение $K$ уменьшается, приближаясь к

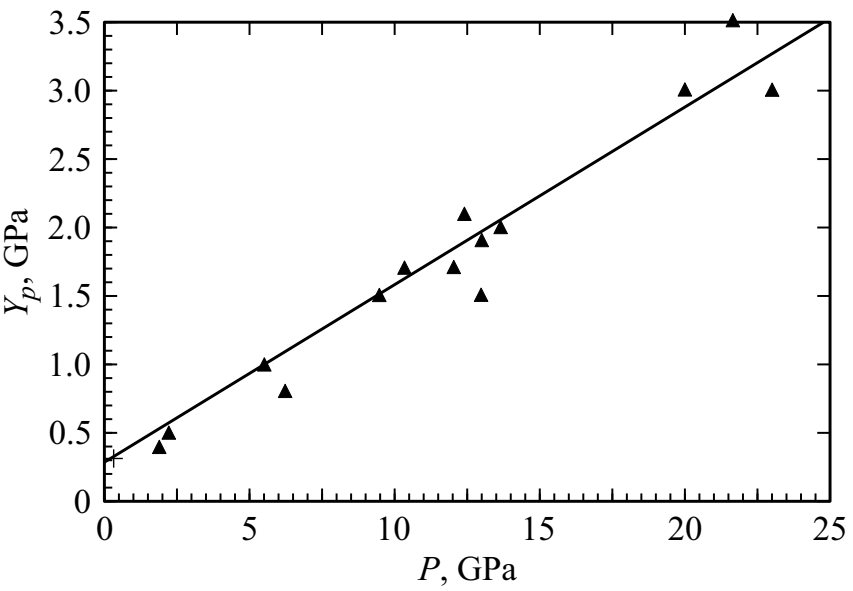

Рис. 2. Зависимость предела текучести меди от давления. $\boldsymbol{\Delta}$ - эксперимент ([4], медь М1); + (в левом нижнем углу) - начало пластической стадии деформирования: $Y_{p}=Y_{*}=0.320 \mathrm{GPa} ;-\quad-Y_{p}=Y_{*}(1-k)+k P$, при $k=0.13 \pm 0.004$.

асимптотическому значению, определяемому формулой М.А. Лаврентьева [13] для случая идеальной несжимаемой жидкости:

$$
K=\sqrt{\rho_{p} / \rho_{t}} .
$$

Наряду с коэффициентом $K$ рассматривается еще один безразмерный коэффициент - коэффициент деформирования $K_{p}=h / \Delta L_{p}\left(\Delta L_{p}-\right.$ укорочение твердой (недеформированной) части ударника вследствие пластического деформирования). В гидродинамическом режиме из-за незначительной (по сравнению с длиной ударника) толщины жидкой фазы материала ударника на контактной границе $\Delta L=\Delta L_{p}$, т. е. $K_{p}=K$. В работе [4] показано (по крайней мере для пары медь+песок), что для скоростей $V$, больших минимальной скорости полного пластического деформирования $\left(V>V_{p}\right)$, но меньших скорости гидродинамического перехода $V_{h t}$, величина $K_{p}$ также не зависит от текущей глубины проникания. В указанных условиях коэффициенты $K$ и $K_{p}$ мало отличаются от начальных:

$$
\begin{gathered}
K_{p}=K_{p 0}=\frac{d h}{d\left(\Delta L_{p}\right)}=\frac{U_{0}}{C_{p}}, \\
K=K_{0}=\frac{d h}{d(\Delta L)}=\frac{U_{0}}{V_{0}-U_{0}},
\end{gathered}
$$

где $U_{0}$ - определяется из (1) с учетом зависимости $Y_{p}\left(V_{0}\right)$.

В работе [4] подробно исследован процесс проникания стержня из меди M1 (предел текучести $\sigma_{0.2} \approx 0.290 \mathrm{GPa}$, плотность $\left.\rho_{p}=8.9 \mathrm{~g} / \mathrm{cm}^{3}\right)$ в песок (плотность $\rho_{t}=1.7 \mathrm{~g} / \mathrm{cm}^{3}$, влажность $W \approx 10 \%$, коэффициент сопротивления $\left.C_{x}=1.5\right)$. Для получения зависимости предела текучести $Y_{p}(P)$ были использованы экспериментальные данные из [11]. На рис. 2 приведены экспериментальные данные $Y_{p}(P)$ [4] и 
их линейная аппроксимация выражением (3), чтобы определить коэффициент упрочнения $k$. В результате экспериментов и расчетов по УМГТ установлено: $V_{*}=0.500 \mathrm{~km} / \mathrm{s} ; \quad k=0.13 ; \quad Y_{*}=0.320 \mathrm{GPa}$; $V_{p}=0.850 \mathrm{~km} / \mathrm{s} ; V_{h t}=1520 \mathrm{~m} / \mathrm{s} ; V_{s h t}=2.100 \mathrm{~km} / \mathrm{s}$.

Для расчета по УМГТ проникания медного ударника зависимость предела текучести материала ударника (в диапазоне $P \leq 25 \mathrm{GPa}$ ) определялась, согласно выражению (4), по следующей формуле:

$$
Y_{p}(V)=Y_{*}(1-k)+k C_{x} \rho_{t} V^{2} / 2 .
$$

Принято, что давление - функция скорости движения твердой (недеформированной) части ударника. Подход в выборе способа оценки давления в формуле предела текучести (8) принят исходя из следующих положений. При высокоскоростном проникании ударника в сплошную среду давление на контактной границе равно $P=\rho_{t} C_{x} U^{2} / 2$ и соответственно, принимая линейную зависимость предела текучести от давления (3), выражение для расчета предела текучести формально должно иметь вид

$$
Y_{p}(U)=Y_{0}+k_{1} C_{x} \rho_{t} U^{2} / 2
$$

где коэффициент $k_{1}$ введен для учета неодномерности деформирования ударника.

В экспериментах по прониканию ударников в преграды известными являются только начальная скорость внедрения $V_{0}$ и плотность преграды и ударника $\rho_{t}$ и $\rho_{p}$. Поэтому в формуле (9) был сделан переход от скорости проникания $U$ к скорости движения твердой части ударника $V$ с использованием их соотношения в гидродинамическом приближении: $U=V /(1+\mu)$ [13]. В нашем случае коэффициент $\mu$ учитывает сжимаемость грунтовой преграды:

$$
\mu=\sqrt{C_{x} \rho_{t} / \rho_{p}} .
$$

Тогда по аналогии с выражением (4) зависимость предела текучести от скорости можно записать как

$$
Y_{p}(V)=Y_{*}\left[1-\frac{k_{1}}{(1+\mu)^{2}}\right]+\frac{k_{1}}{(1+\mu)^{2}} C_{x} \rho_{t} V^{2} / 2
$$

Величина $(1+\mu)^{2}$ определяется плотностью ударника и преграды и коэффициентом сопротивления.

Чтобы определить значение коэффициента $k_{1}$, использовались экспериментальные данные по коэффициенту относительного проникания $K$ при движении медного ударника в песчаном грунте, полученные при разных начальных скоростях $V_{0}>V_{p}$ (табл. 1). Используя уравнение (1) и считая $K$ стационарным при скорости внедрения $V_{0}>V_{p}$, можно записать в развернутом виде

$$
K(V)=\frac{d h}{d(\Delta L)}=K\left(V_{0}\right)=\frac{U_{0}}{V_{0}-U_{0}}=\sqrt{\frac{\rho_{p}}{C_{x} \rho_{t}}} \sqrt{\frac{1}{1-\frac{2 Y_{p}\left(V_{0}\right)}{C_{x} \rho_{t} U_{0}^{2}}}}
$$

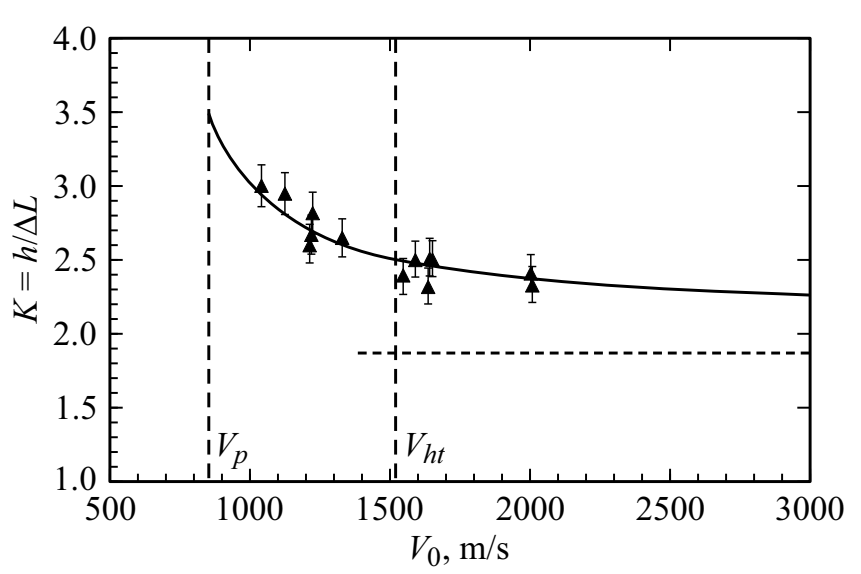

Рис. 3. Экспериментальные значения коэффициента относительного проникания $K$ медного ударника в песке. $\boldsymbol{\Delta}-$ эксперимент (табл. 1 , разброс $\pm 5 \%$ ); -- аппроксимация аналитической зависимостью $\left.(10), Y_{p}=Y\right) p(V)$ с учетом (8), (11) с коэффициентом $k=0.128, Y_{*}=0.320 \mathrm{GPa}\left(V_{*}=500 \mathrm{~m} / \mathrm{s}\right)$.

Для определения коэффициента $k_{1}$ подставим формулу (11) для предела текучести $Y_{p}(V)$ в уравнение (1) при $U=U_{0}$ :

$$
\begin{aligned}
& U_{0}=\frac{V_{0}}{1-\mu^{2}\left(1-k_{1}\right)} \\
& \times\left[1-\sqrt{1-\left(1-\mu^{2}\left(1-k_{1}\right)\right)\left[1+\left(1-k_{1}\right) \mu^{2} V_{*}^{2} / V_{0}^{2}\right]}\right]
\end{aligned}
$$

Аппроксимация методом наименьших квадратов экспериментальных данных по коэффициенту относительного проникания $K$ медного ударника выражением (10f) с учетом (11) и (13) дает значение $k_{1}=0.302 \pm 0.005$ (приведено расчетное среднеквадратическое отклонение). В случае проникания медного ударника в песок значение коэффициента (10) $\mu=0.535$, тогда значение коэффициента упрочнения в соотношении (11) $k=k_{1} /(1+\mu)^{2}=0.128 \pm 0.002$. Аппроксимирующая зависимость коэффициента относительного проникания медного ударника показана на рис. 3. Полученное значение $k=0.128 \pm 0.002$ практически равно значению коэффициента упрочнения $k=0.13 \pm 0.004$, рассчитанному по данным прямых опытов с плоской ударной волной (рис. 2). Таким образом, замена скорости $U$ на $V$ в оценке реализующегося давления позволяет использовать выражение (8) для расчета предела текучести материала ударника, используя значение коэффициента упрочнения $k$, полученное из прямых опытов определения $Y(P)$. В этом случае выражение (13) для скорости проникания, учитывая зависимость предела текучести по формуле (8), будет иметь следующий вид:

$$
U_{0}=\frac{V}{1-\mu^{2}}\left[1-\mu \sqrt{1-\left(1-\mu^{2}\right)\left[k+(1-k) V_{*}^{2} / V_{0}^{2}\right]}\right] .
$$


Таблица 1. Опыты с ударниками из меди М1 при проникании в песок [4]

\begin{tabular}{c|c|c|c|c|c|c|c|c|c|c|c|c}
\hline \multicolumn{10}{c}{ Пластический режим } \\
\hline \multirow{2}{*}{$V_{0}, \mathrm{~km} / \mathrm{s}$} & $\begin{array}{c}h, \\
\mathrm{~mm}\end{array}$ & $t_{p}, \mu \mathrm{s}$ & $\begin{array}{c}\Delta L, \\
\mathrm{~mm}\end{array}$ & $\begin{array}{c}\Delta L_{p}, \\
\mathrm{~mm}\end{array}$ & $K_{p}=h / \Delta L_{p}$ & $K=h / \Delta L$ & $\begin{array}{c}C_{p}=\Delta L_{p} / t, \\
\mathrm{~m} / \mathrm{s}\end{array}$ & $t, \mu \mathrm{s}$ & $\begin{array}{c}\Delta L, \\
\mathrm{~mm}\end{array}$ & $\begin{array}{c}\Delta L_{p}, \\
\mathrm{~mm}\end{array}$ & $K p=h / \Delta L_{p}$ & $\begin{array}{c}K=h / \Delta L ; \\
\delta, \%\end{array}$ \\
\hline 0.703 & 27.5 & 44.2 & 5.5 & 20.0 & 1.37 & 5.00 & 452 & 48.1 & 5.7 & 21 & 1.31 & $4.82(-3.6)$ \\
\hline 0.853 & 70.0 & 96.8 & 19.0 & 42 & 1.67 & 3.68 & 434 & 109.4 & 19.3 & 47.8 & 1.46 & $3.63(-1.4)$ \\
\hline 0.879 & 65.0 & 93.8 & 20.0 & 41 & 1.58 & 3.25 & 437 & 98.9 & 18.7 & 43.2 & 1.51 & $3.48(7.0)$ \\
\hline 0.965 & 62.0 & 81.9 & 19.5 & 35 & 1.77 & 3.18 & 427 & 87.4 & 19.7 & 38.2 & 1.62 & $3.15(-1.0)$ \\
\hline 1.080 & 57.0 & 67.8 & 19.0 & 30 & 1.90 & 3.00 & 442 & 72.9 & 19.3 & 31.8 & 1.79 & $2.95(-1.7)$ \\
\hline 1.125 & 53.0 & 61.0 & 18.0 & 27 & 1.89 & 2.94 & 443 & 65.3 & 18.9 & 28.5 & 1.86 & $2.80(-4.8)$ \\
\hline 1.214 & 125 & 136 & 48.0 & 58 & 2.15 & 2.60 & 426 & 149.4 & 45.3 & 65.3 & 1.91 & $2.76(6.1)$ \\
\hline 1.218 & 120 & 141 & 45.0 & 60 & 2.00 & 2.67 & 426 & 142.5 & 43.7 & 62.2 & 1.93 & $2.75(3.0)$ \\
\hline 1.225 & 90 & 96 & 32.0 & 42 & 2.14 & 2.81 & 438 & 104.4 & 33.2 & 45.6 & 1.97 & $2.71(-3.6)$ \\
\hline 1.330 & 102 & 104 & 38.5 & 46 & 2.21 & 2.65 & 442 & 110.3 & 39.0 & 48.2 & 2.12 & $2.62(-1.1)$
\end{tabular}

\begin{tabular}{|c|c|c|c|c|c|c|c|}
\hline \multicolumn{8}{|c|}{ Гидродинамический режим } \\
\hline \multirow{2}{*}{$V_{0}, \mathrm{~km} / \mathrm{s}$} & \multicolumn{4}{|c|}{ Экспериментальные данные } & \multicolumn{3}{|c|}{ Расчет по УМГТ } \\
\hline & $h, \mathrm{~mm}$ & $t_{p}, \mu \mathrm{s}$ & $\Delta L, \mathrm{~mm}$ & $K=h / \Delta L$ & $t, \mu \mathrm{s}$ & $\Delta L, \mathrm{~mm}$ & $K=h / \Delta L ;(\delta \%)$ \\
\hline 1.544 & 105 & 104 & 44 & 2.39 & 98.8 & 42.3 & $2.48(3.8)$ \\
\hline 1.590 & 155 & 153 & 62 & 2.50 & 145.3 & 62.4 & $2.48(-1.0)$ \\
\hline 1.636 & 65 & 58.4 & 28 & 2.32 & 57.0 & 26.7 & $2.43(4.7)$ \\
\hline 1.639 & 63 & 60 & 25 & 2.52 & 55.2 & 25.9 & $2.43(-3.6)$ \\
\hline 1.650 & 105 & 97 & 42 & 2.50 & 92.8 & 43.0 & $2.44(-2.4)$ \\
\hline 2.000 & 125 & 102 & 52 & 2.40 & 92.5 & 53.2 & $2.35(-2.0)$ \\
\hline 2.006 & 135 & 110 & 58 & 2.33 & 100.2 & 57.4 & $2.35(1.0)$ \\
\hline
\end{tabular}

\section{2. Постановка экспериментов}

Применение УМГТ [4] для меди М1 базировалось на известных из $[11]$ коэффициентах зависимости $Y_{p}(P)$. Для вольфрамового сплава ВНЖ и стали 30ХГСА нам такая зависимость не известна, именно это обстоятельство и явилось поводом определения $Y_{p}(P)$ для данных металлов по результатам экспериментов по высокоскоростному прониканию цилиндрических ударников из сплава ВНЖ и стали 30ХГСА. Эксперименты по исследованию процесса проникания в грунт металлических ударников проводились с помощью метательных баллистических установок [14]: при скоростях метания до $1.5 \mathrm{~km} / \mathrm{s}$ использовалась пороховая установка, при больших скоростях метания - двухступенчатые легкогазовые установки.

На рис. 4, $a$ приведена схема постановки опытов $[9,15,16]: 1-$ регистратор, 2 - катушки,
3 - магниты, 4 - ствольная баллистическая установка, 5 - контейнер с песком, 6 - камера „ЭПОС“ или рентгеновский аппарат (РА) „Аргумент-120“, 7 - РА „Аргумент-120“. Регистрация положения ударника перед входом в грунт осуществлялась РА „Аргумент-120“ или фотооптической системой „ЭПОС“, а регистрация движущегося в грунте ударника осуществлялась с помощью РА „Аргумент-120“6 [9].

На рис. 4, $b$ приведена фотография ударника из сплава ВНЖ в воздухе перед внедрением в контейнер с песком. Сзади летят расходящиеся в сторону лепестки дюралюминиевого поддона, впереди вертикальная линия струна, выполняющая роль отвеса, позволяет оценить возможный начальный угол атаки.

Грунтовая преграда представляла собой контейнер, заполненный песком, шириной $5-10 \mathrm{~cm}$ в зависимости от диаметра проникающего ударника. В опытах в основном использовался мелкозернистый песок плотно- 


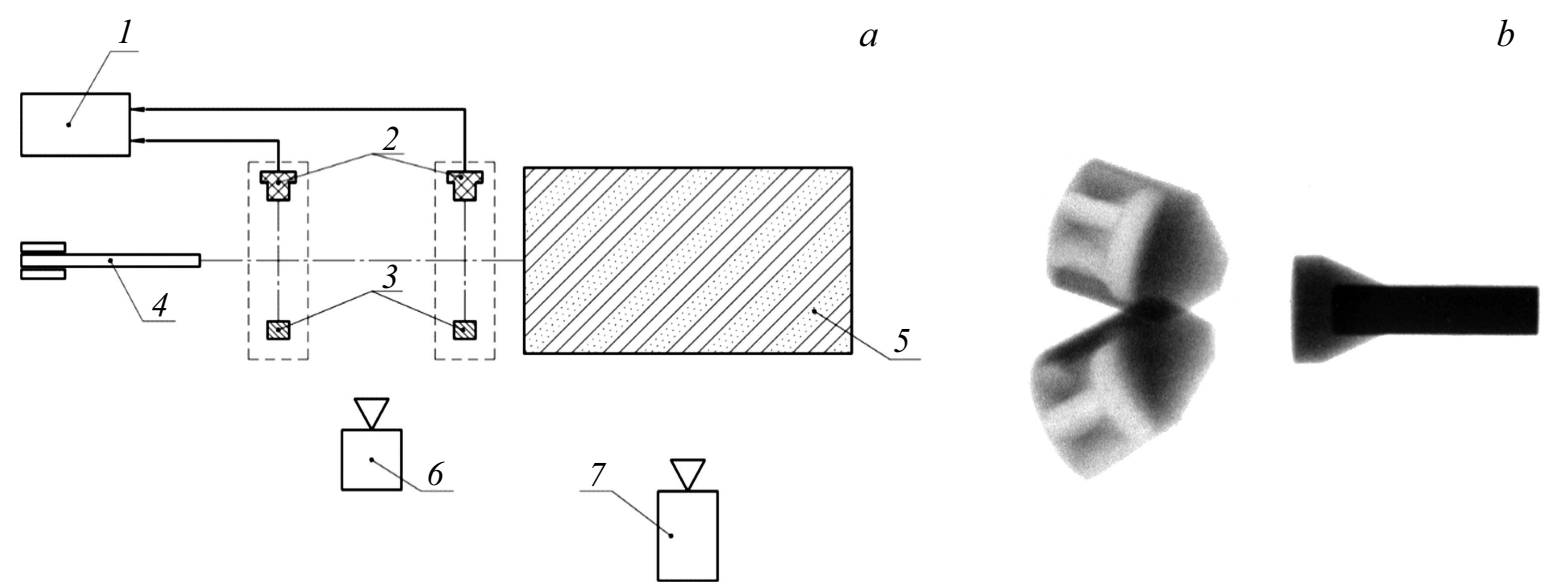

Pис. 4. Схема проведения опытов $(a)$ и ударник из сплава ВНЖ в полете $(b)$.

Таблица 2. Опыты с ударниками из стали 30ХГСА при проникании в песок

\begin{tabular}{|c|c|c|c|c|c|c|c|c|c|c|c|c|c|}
\hline \multirow{2}{*}{ № п/ா } & \multirow{2}{*}{$V_{0}, \mathrm{~km} / \mathrm{s}$} & \multirow{2}{*}{$m, \mathrm{~g}$} & \multirow{2}{*}{$d_{k}, \mathrm{~mm}$} & \multirow{2}{*}{$\rho_{t}, \mathrm{~g} / \mathrm{cm}^{3}$} & \multirow{2}{*}{$W, \%$} & \multirow{2}{*}{$h, \mathrm{~mm}$} & \multirow{2}{*}{$\Delta L, \mathrm{~mm}$} & \multirow{2}{*}{$t_{p}, \mu \mathrm{s}$} & \multirow{2}{*}{$K=h / \Delta L$} & \multirow{2}{*}{$C_{x}$} & \multicolumn{3}{|c|}{ Расчет по УМГТ } \\
\hline & & & & & & & & & & & $\Delta L, \mathrm{~mm}$ & $t, \mu \mathrm{s}$ & $K(\delta \%)$ \\
\hline \multicolumn{14}{|c|}{ Пластический режим } \\
\hline 1 & 1.928 & 60.0 & 11.25 & 1.76 & 9.6 & 51.0 & 17.0 & 34.7 & 3.0 & 1.5 & 15.8 & 35.8 & $3.23(7)$ \\
\hline 2 & 1.963 & 60.0 & 11.25 & 1.85 & 12 & 37.0 & 12.0 & 23.8 & 3.1 & 1.4 & 11.6 & 25.3 & $3.19(3)$ \\
\hline 3 & 1.969 & 60.0 & 11.25 & 1.78 & 9.6 & 72.0 & 24.0 & 50.7 & 3.0 & 1.5 & 22.7 & 50.4 & $3.17(5)$ \\
\hline \multicolumn{14}{|c|}{ Гидродинамический режим } \\
\hline 4 & 2.293 & 60.0 & 11.25 & 1.85 & 9.0 & 45.0 & 16.0 & 24.7 & 2.81 & 1.5 & 16.4 & 27.5 & $2.74(-2)$ \\
\hline 5 & 2.358 & 60.0 & 11.25 & 1.80 & 10 & 60.0 & 22.0 & 34.5 & 2.73 & 1.5 & 21.8 & 35.8 & $2.75(1)$ \\
\hline
\end{tabular}

стью и влажностью в диапазоне $\rho_{t} \approx(1.6-1.8) \mathrm{g} / \mathrm{cm}^{3}$ и $W \approx(8-12) \%$. В пяти опытах с ударником из сплава ВНЖ [5] использовался практически сухой песок. Стержневые ударники из меди М1, сплава ВНЖ и стали 30ХГСА имели диаметр переднего торца $d_{k} \approx 4-11 \mathrm{~mm}$, длину $L_{0}=30-80 \mathrm{~mm}$, массу $m=7-60 \mathrm{~g}$.

Экспериментальные данные, включая фактические параметры песчаного грунта и ударников, представлены в табл. 1-3. В этих таблицах приведены также значения, рассчитанные по УМГТ, сравнение с экспериментальными данными проводилось для значений $V_{0}$ и $h$ конкретного опыта. Значение скорости пластической волны приведено в табл. 4. Начальные данные для расчетов по УМГТ следующие:

- опыты [4] с ударниками из меди M1 (табл. 1): средние значения параметров грунта: $\rho_{t}=1.7 \mathrm{~g} / \mathrm{cm}^{3}$, $W=10 \% \quad\left(Y_{*}=0.320 \mathrm{GPa}, k=0.13 ; C_{x}=1.5\right)$, параметры ударника: $d=10 \mathrm{~mm}, m=57.5 \mathrm{~g}, \rho_{p}=8.9 \mathrm{~g} / \mathrm{cm}^{3}$, $\sigma_{0.2} \approx 0.290 \mathrm{GPa}$;

- опыты с ударниками из стали 30ХГСА (табл. 2): $Y_{*}=1.34 \mathrm{GPa}, \quad k=0.175, \quad$ параметры ударника: $d_{m}=22.5 \mathrm{~mm}, \rho_{p}=7.85 \mathrm{~g} / \mathrm{cm}^{3}, \sigma_{t} \approx 1.100 \mathrm{GPa}$ (сталь средней прочности [17]);
- опыты с ударниками из сплава ВНЖ (табл. 3) [5]: $Y_{*}=1.775 \mathrm{GPa}, k=0.25, \rho_{p}=17.0 \mathrm{~g} / \mathrm{cm}^{3}$, значения массы $\mathrm{m}$ и диаметра $d$ ударника приведены в таблице, $\sigma_{t} \approx 0.877 \mathrm{GPa}[5]$.

Экспериментальные глубина проникания $h$, сработавшаяся $\Delta L$ и деформированная (для медного стержня) $\Delta L_{p}$ часть ударника получены при обработке рентгенограмм процесса проникания на момент времени $t_{p}$ [9]. На рис. 5 представлены характерные рентгенограммы процесса проникания в песок ударников из меди М1, стали 30ХГСА $\left(d_{m}\right.$ - диаметр миделя) и сплава ВНЖ.

Приведенные в табл. 1-4 экспериментальные значения коэффициента сопротивления имеют среднеквадратическое отклонение не менее $(2-3) \%$ [10] (с учетом погрешности определения параметров песка). Общая погрешность определения экспериментального $C_{x}$ может достигать $10 \%$.

\section{3. Результаты измерений}

В опытах непосредственно измеряются:

- $\rho_{t}$ - плотность песка; 
Таблица 3. Опыты с ударниками из сплава ВНЖ при проникании в песок [5]

\begin{tabular}{|c|c|c|c|c|c|c|c|c|c|c|c|c|c|}
\hline \multirow{2}{*}{ № п/п } & \multirow{2}{*}{$V_{0}, \mathrm{~km} / \mathrm{s}$} & \multirow{2}{*}{$m, \mathrm{~g}$} & \multirow{2}{*}{$d_{k}, \mathrm{~mm}$} & \multirow{2}{*}{$\rho_{t}, \mathrm{~g} / \mathrm{cm}^{3}$} & \multirow{2}{*}{$W, \%$} & \multirow{2}{*}{$h, \mathrm{~mm}$} & \multirow{2}{*}{$\Delta L, \mathrm{~mm}$} & \multirow{2}{*}{$t_{p}, \mu \mathrm{s}$} & \multirow{2}{*}{$K=h / \Delta L$} & \multirow{2}{*}{$C_{x}$} & \multicolumn{3}{|c|}{ Расчет по УМГТ } \\
\hline & & & & & & & & & & & $\Delta L, \mathrm{~mm}$ & $t, \mu \mathrm{s}$ & $K(\delta \%)$ \\
\hline \multicolumn{14}{|c|}{ Пластический режим } \\
\hline 1 & 1.560 & 25.85 & 7 & $\approx 1.7$ & $\approx 10$ & 55.0 & 6.2 & 39.2 & 8.87 & 1.5 & 6.5 & 41.5 & $8.46(-5)$ \\
\hline 2 & 1.840 & 24.10 & 7 & $\approx 1.7$ & $\approx 10$ & 57.1 & 11.9 & 37.5 & 4.80 & 1.5 & 9.8 & 38.0 & $5.8(20)$ \\
\hline 3 & 1.950 & 24.05 & 7 & $\approx 1.7$ & $\approx 10$ & 63.4 & 14.5 & 39.8 & 4.37 & 1.5 & 11.7 & 40.4 & $5.41(28)$ \\
\hline 4 & 2.000 & 24.25 & 7 & $\approx 1.7$ & $\approx 10$ & 87.1 & 17.5 & 54.1 & 4.98 & 1.5 & 16.1 & 55.3 & $5.4(8)$ \\
\hline \multicolumn{14}{|c|}{ Гидродинамический режим } \\
\hline 5 & 2.520 & 24.05 & 7.04 & 1.6 & 1.4 & 36.1 & 9.5 & 17.7 & 3.80 & 2.0 & 9.6 & 18.6 & $3.76(-1)$ \\
\hline 6 & 2.590 & 7.75 & 4.06 & 1.76 & 11.3 & 60.6 & 15.8 & 29.9 & 3.85 & 1.5 & 14.5 & 30.1 & $4.17(8)$ \\
\hline 7 & 2.600 & 7.70 & 4.05 & 1.725 & 8.2 & 47.5 & 12.8 & 23.4 & 3.71 & 1.65 & 12.0 & 23.6 & $3.96(7)$ \\
\hline 8 & 2.620 & 7.75 & 4.02 & 1.825 & 10.9 & 36.0 & 9.0 & 16.8 & 4.0 & 1.5 & 8.91 & 17.5 & $4.04(1)$ \\
\hline 9 & 2.650 & 7.75 & 4.01 & 1.835 & 11.2 & 62.7 & 17.2 & 30.3 & 3.65 & 1.5 & 15.5 & 30.8 & $4.04(10)$ \\
\hline 10 & 3.370 & 24.25 & 7.02 & 1.66 & 1.55 & 31.1 & 8.7 & 12.6 & 3.57 & 2.0 & 9.2 & 12.2 & $3.38(-5)$ \\
\hline 11 & 3.370 & 24.25 & 7.05 & 1.77 & 10.8 & 42.4 & 11.5 & 15.8 & 3.68 & 1.5 & 11.3 & 16.2 & $3.75(2)$ \\
\hline 12 & 3.380 & 24.10 & 7.025 & 1.56 & 0.6 & 58.7 & 16.6 & 22.2 & 3.53 & 2.0 & 16.9 & 23.2 & $3.47(-2)$ \\
\hline 13 & 3.400 & 7.70 & 4.04 & 1.72 & 8.6 & 57.3 & 15.6 & 21.2 & 3.67 & 1.6 & 15.5 & 22.1 & $3.70(1)$ \\
\hline 14 & 3.490 & 7.7 & 4.05 & 1.64 & 1.1 & 47.3 & 13.1 & 16.7 & 3.61 & 2.0 & 14.1 & 18.1 & $3.36(-7)$ \\
\hline 15 & 3.570 & 7.50 & 3.96 & 1.66 & 0.8 & 43.8 & 13.2 & 15.8 & 3.32 & 2.0 & 13.2 & 16.4 & $3.32(0)$ \\
\hline
\end{tabular}

Таблица 4. Значения средних параметров грунта, при которых проводилась оценка коэффициента упрочнения $k$, значения $Y_{*}$ и $C_{p}$ при расчете проникания ударников по УМГТ (результаты в табл. $1-3$ )

\begin{tabular}{|c|c|c|c|c|c|c|c|c|c|}
\hline \multirow{2}{*}{ Материал ударника } & \multirow{2}{*}{$\rho_{p}, \mathrm{~g} / \mathrm{cm}^{3}$} & \multirow{2}{*}{$\begin{array}{c}V_{*}, \mathrm{~km} / \mathrm{s} \\
\text { (параметры грунта) }\end{array}$} & \multirow{2}{*}{$Y_{*}, \mathrm{GPa}$} & \multicolumn{3}{|c|}{ Средние значения } & \multirow{2}{*}{$k$} & \multirow{2}{*}{$H B, \mathrm{GPa}$} & \multirow{2}{*}{$C_{p}, \mathrm{~km} / \mathrm{s}$} \\
\hline & & & & $C_{x}$ & $\rho_{b}, \mathrm{~g} / \mathrm{cm}^{3}$ & $W, \%$ & & & \\
\hline Медь М1 & 8.9 & $\begin{array}{c}0.500[4] \\
\left(\rho_{t}=1.7 \mathrm{~g} / \mathrm{cm}^{3}, W=10 \%, C_{x}=1.5\right)\end{array}$ & 0.32 & 1.5 & 1.7 & 10 & 0.13 & - & 0.437 \\
\hline Сплав ВНЖ90 & 17.0 & $\begin{array}{c}1.180[5] \\
\left(\rho_{t}=1.7 \mathrm{~g} / \mathrm{cm}^{3}, W=10 \%, C_{x}=1.5\right)\end{array}$ & 1.775 & 1.75 & 1.7 & 7.0 & 0.25 & $2.365[5]$ & 0.346 \\
\hline Сталь 30ХГСА & 7.85 & $\begin{array}{c}1.000 \\
\left(\rho_{t}=1.8 \mathrm{~g} / \mathrm{cm}^{3}, W=10 \%, C_{x}=1.5\right)\end{array}$ & 1.34 & 1.5 & 1.8 & 10 & 0.175 & $2.20[17]$ & 0.492 \\
\hline
\end{tabular}

- $W$ - весовая влажность песка;

$-C_{x}$ - коэффициент сопротивления плоского торца стержня (в специально поставленных опытах [10]);

- $V_{0}$ - начальная скорость внедрения в преграду;

- $h$ - текущая глубина проникания по рентгенограмме;

- $t_{p}$ - момент времени рентгенографирования от контакта ударника с лицевой поверхностью грунтовой преграды до срабатывания рентгеновского аппарата;

- $V_{*}$ - критическая скорость проникания (определяется в серии однотипных опытов путем наращивания скорости внедрения в песчаный грунт с конкретными параметрами плотности и влажности);

- $\Delta L, \Delta L_{p}$ - укорочение ударника $\left(\Delta L=L_{0}-L\right)$ и укорочение твердой части ударника вследствие пластического деформирования $\left(\Delta L_{p}=L_{0}-L_{p}\right)$ (рис. 1$)$.

Величина $L_{p}$ отсчитывается от заднего торца цилиндра до фронта продольной пластической волны, положение которого определяется сечением ударника с минимальным увеличением диаметра стержня относительно начального (в наших экспериментальных исследованиях рассматривалось увеличение диаметра до 10\%). 


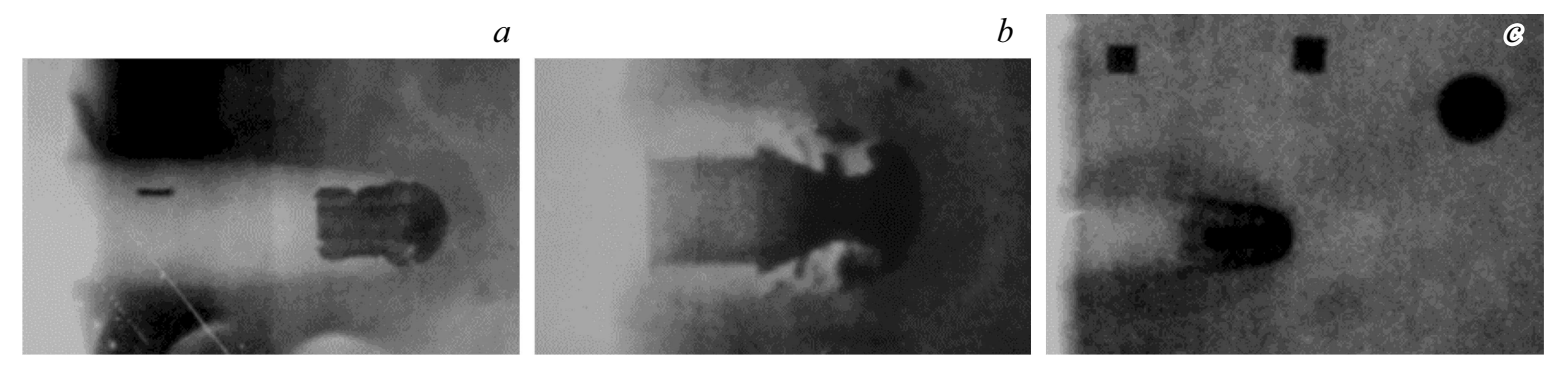

Рис. 5. Характерные рентгенограммы при проникании в песчаный грунт: $a$ - ударник из меди $\mathrm{M} 1\left(d=10 \mathrm{~mm}, L_{0}=82.2 \mathrm{~mm}\right)$, $V_{0}=1.214 \mathrm{~km} / \mathrm{s}, \rho_{t}=1.7 \mathrm{~g} / \mathrm{cm}^{3} ; b$ - ударник из стали 30 ХГСА $\left(d_{k}=11.25 \mathrm{~mm}, d_{m}=22.5 \mathrm{~mm}, L_{0}=60 \mathrm{~mm}\right), V_{0}=1.928 \mathrm{~km} / \mathrm{s}$, $\rho_{t}=1.8 \mathrm{~g} / \mathrm{cm}^{3} ; c-$ ударник из сплава ВНЖ $\left(d=4 \mathrm{~mm}, L_{0}=30 \mathrm{~mm}\right), V_{0}=3.570 \mathrm{~km} / \mathrm{s}, \rho_{t}=1.66 \mathrm{~g} / \mathrm{cm}^{3}$.

В табл. 4 приведены полученные экспериментальные значения $V_{*}$ при конкретных параметрах песка, средние значения $\rho_{t}, W$ и $C_{x}$ по количеству проведенных опытов, по которым проводилась аппроксимация экспериментальных зависимостей $K\left(V_{0}\right)$, чтобы определить коэффициент упрочнения $k$ данного металла. Также в табл. 4 приведены значения $Y_{*}$, определенные непосредственно из формулы (2), исходя из экспериментально полученного значения $V_{*}$, плотности материала ударника $\rho_{p}$, коэффициента упрочнения $k$, определенного аппроксимацией экспериментальной зависимости $K\left(V_{0}\right)$ выражением (10), величины твердости по Бринеллю материала ударника $H B$ и $C_{p}-$ скорости продольной пластической волны для данного металла.

Скорость продольной пластической волны в опытах с медным ударником [4] определена из экспериментов путем измерения недеформированной части стержня $L_{p}$ по рентгенограммам и времени $t$ регистрации процесса проникания. Для сплава ВНЖ и стали 30ХГСА величина $C_{p}$ оценивалась теоретически. В работе [7] на основе экспериментов с достаточно прочными металлами для оценки скорости продольной пластической волны предложена эмпирическая формула, использующая твердость материала по Бринеллю:

$$
C_{p}=\sqrt{\frac{0.863 \cdot H B}{\rho_{p}}} .
$$

Для стали 30ХГСА принято значение твердости $H B=2.20 \mathrm{GPa}$ [17]. Для сплава ВНЖ принята величина твердости $H B=2.365 \mathrm{GPa}$ [5], измеренная на заготовках, из которых вытачивались ударники.

\section{4. Система уравнений УМгТ. Определение коэффициента упрочнения}

В классическую систему уравнений МГТ, описывающую процесс проникания, были добавлены уравнения для пластической стадии деформирования, а величина $Y_{p}$ (как динамический предел текучести материала ударника [1]) принята зависящей от скорости проникания [4].
Проникание в режиме „твердого тела“ в настоящей работе не рассматривается: скорость твердой части ударника $\mathrm{V}$ может изменяться от $V_{0}$ до $V_{*}$. В течение этого процесса будет изменяться и предел текучести материала ударника. Как было сказано выше, был введен также учет сжимаемости песчаного грунта через коэффициент сопротивления $C_{x}$ плоского торца.

Полная система уравнений, описывающая процесс проникания как в пластической, так и гидродинамической стадиях деформирования с учетом выражений (1), (2), (5), (8) имеет вид [4]:

$$
\begin{gathered}
\frac{d h}{d t}=U, \\
\rho_{p} L_{p} \frac{d V}{d t}=-Y_{p}(V), \\
\frac{d L_{p}}{d t}=-C_{p}, \text { при } V_{*} \leq V<V_{h t}, \\
\frac{d L}{d t}=-(V-U), L_{p}=L \text { при } V \geq V_{h t} .
\end{gathered}
$$

Так как отсутствуют прямые экспериментальные данные по зависимости предела текучести сплава ВНЖ и стали 30ХГСА от создаваемого продольного напряжения $\sigma_{x}$, для определения $Y_{p}(P)$ будем использовать результаты экспериментов по внедрению в песок ударников из этих металлов (табл. 2, 3). Зависимость предела текучести от скорости определяется выражением (8), оценка коэффициента упрочнения осуществляется по аппроксимации экспериментальной зависимости коэффициента относительного проникания от начальной скорости внедрения $K\left(V_{0}\right)$ (формула $(10)$ ) с усредненными параметрами песчаного грунта (табл. 4).

Как показано в [4], для медного стержня коэффициент относительного проникания является практически постоянным в процессе проникания, по крайней мере в гидродинамической стадии и в пластической стадии при $V>V_{p}$. Для проверки стационарности данного коэффициента сгруппируем эксперименты с ударниками из прочных материалов (сталь 30ХГСА и сплав ВНЖ (табл. 2,3)) по близким начальным скоростям внедрения. 

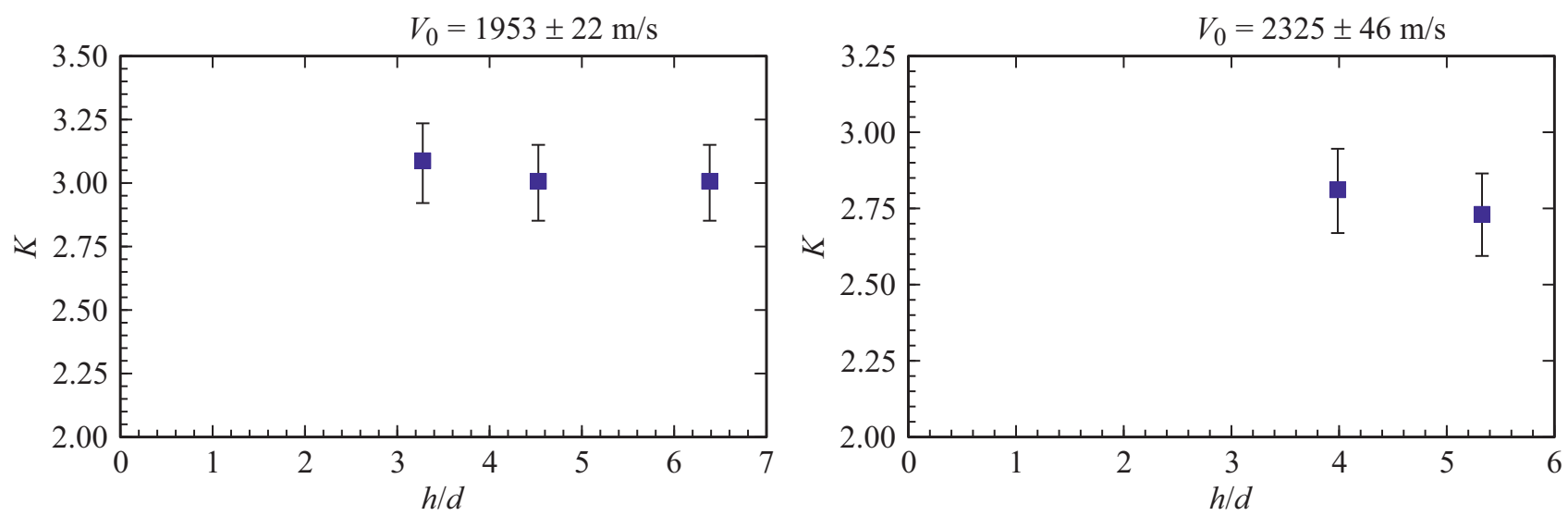

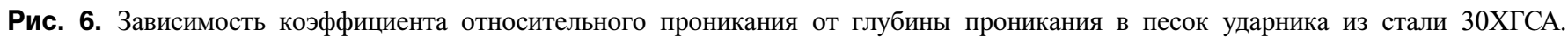

- эксперимент (табл. 2, разброс $\pm 5 \%$ ).
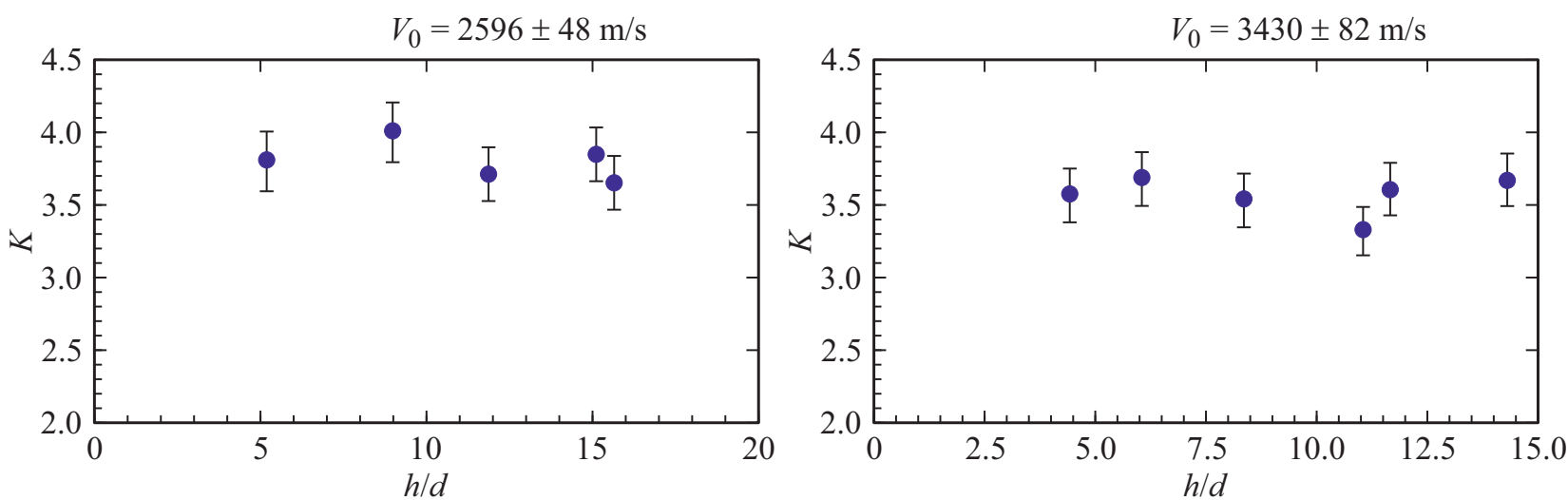

Рис. 7. Зависимость коэффициента относительного проникания от глубины проникания в песок ударника из сплава ВНЖ90. - - эксперимент (табл. 3, разброс $\pm 5 \%$ ).

Для обоих металлов было выделено по две группы экспериментов при средней начальной скорости внедрения:

$V_{0}=(1.953 \pm 0.022$ и $2.325 \pm 0.046 \mathrm{~km} / \mathrm{s})$ - для ста-

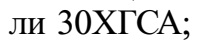

$V_{0}=(2.596 \pm 0.04848$ и $3.430 \pm 0.082 \mathrm{~km} / \mathrm{s})$ - для сплава ВНЖ.

При близких начальных скоростях внедрения $V_{0}$ в разных опытах (разброс от среднего значения не более $3 \%$ ) глубина проникания, на которой фиксировался коэффициент относительного проникания, была существенно различной.

На рис. 6 и 7 приведены графики экспериментальной зависимости коэффициента относительного проникания от глубины проникания для ударника из стали 30ХГСА и сплава ВНЖ. В первом приближении коэффициент относительного проникания, определенный на разных глубинах, можно для данной средней скорости внедрения считать постоянным в пределах экспериментальной погрешности $\pm 5 \%$. Соответственно каждое значение $K$, приведенное в табл. 2 и 3 для конкретного значения $h$ и текущего значения $V$, может быть отнесено и к $h_{0}$, и к $V_{0}$.
Для каждого металла определяется экспериментальная зависимость $K=f\left(V_{0}\right)$, которая аппроксимируется аналитической зависимостью (12). По этой аппроксимации с учетом выражений (14) и (8) методом наименьших квадратов определяется величина коэффициента упрочнения $k$ конкретного металла. Аппроксимационные зависимости для сплава ВНЖ и стали 30ХГСА приведены на рис. 8 и 9, а полученные значения коэффициентов упрочнения $k-$ в табл. 4 .

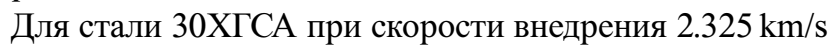
приведены только два эксперимента, но, исходя из опытов с другой скоростью, в том числе с ударником из сплава ВНЖ, нет оснований сомневаться в стационарности коэффициента относительного проникания.

\section{5. Результаты расчетов по УМГТ проникания в песок металлических стержней}

В табл. 1-3 приведены исходные данные, при которых проводились опыты и расчеты по УМГТ. Расчеты проникания в песок исследованных ударников проводились, 


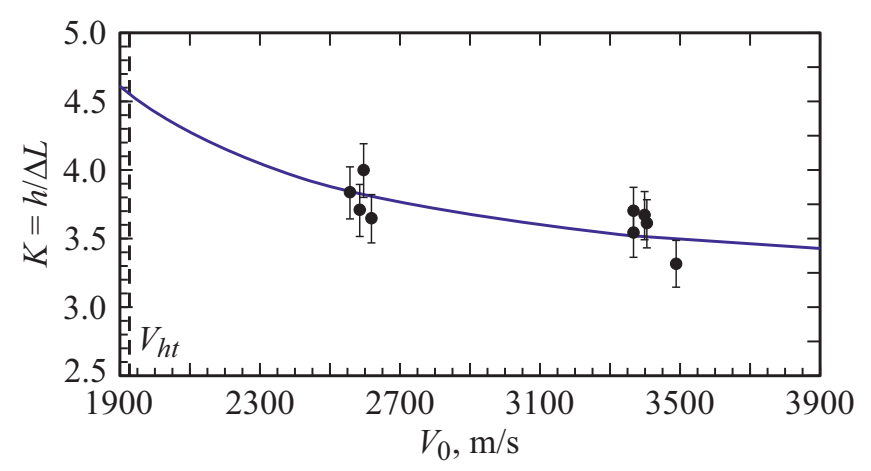

Рис. 8. Зависимость коэффициента относительного проникания в песок стержня из сплава ВНЖ. - - эксперимент (табл. 3, разброс $\pm 5 \%$ ), - - аппроксимация аналитической зависимостью (12), $Y_{p}=Y_{p}(V)$ с учетом (14) и (8) с коэффициентом $k=0.25, Y_{*}=1.775 \mathrm{GPa}$.

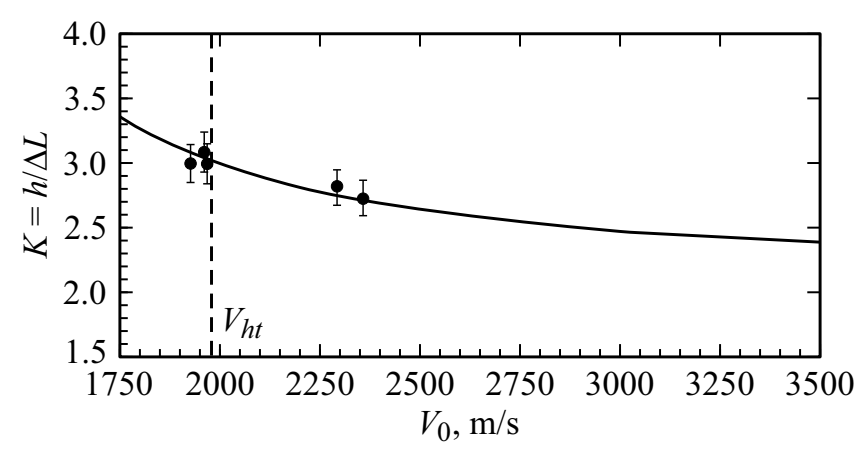

Рис. 9. Зависимость коэффициента относительного проникания в песок стержня из стали 30ХГСА: - - эксперимент (табл. 2, разброс $\pm 5 \%$ ), - - аппроксимация аналитической зависимостью $(12), Y_{p}=Y_{p}(V)$ с учетом (14) и (8) с коэффициентом $k=0.175, Y_{*}=1.34 \mathrm{GPa}$.

согласно системе уравнений (1), (2), (5), (8), (15)-(18) с задаваемыми исходными данными, а именно

- значениями $Y_{*}, C_{p}, V_{0}, k$;

- параметрами песчаного грунта $\left(C_{x}, \rho_{t}\right)$;

- параметрами металлических стержней $(m, d$, $\left.L_{0}, \rho_{p}\right)$.

Величина укорочения твердой части ударника $\Delta L_{p}$ вследствие пластического деформирования определялась только в случае медного ударника. В последних столбцах табл. 1-3 приведены значения, рассчитанные по УМГТ. Сравнение с экспериментом проводилось для фиксированных значений $V_{0}$ и $h$. В таблицах также приведены экспериментальные значения коэффициента деформирования $K_{p}=h / \Delta L$ (в пластической стадии для медного стержня) и коэффициента относительного проникания $K=h / \Delta L$ для обеих стадий проникания. Отличие расчетных значений $t, \Delta L, K$ для трех материалов ударников и $\Delta L_{p}, K_{p}$ для медного ударника от экспериментально полученных значений составило величину не более $5-10 \%$.
В табл. 5 приведены расчетные значения скоростей $V_{*}, V+p, V_{h t}$ и $V_{s h t}$ для внедрения ударников из трех исследованных материалов в песок (значение $V_{*}$ рассчитано по формуле (2), согласно значению $Y_{*}$ (табл. 4), которые определяют характерные скоростные интервалы, в которых качественно отличается глубина окончания деформирования.

Расчеты для прочных металлов - сплава ВНЖ и стали 30ХГСА, так же как и для меди М1 [4], показали наличие четырех характерных диапазонов скорости проникания:

Диапазон I $\left(V_{*} \leq V_{0}<V_{h t}\right)$ : ударник, пластически деформируясь, не достигнув полного пластического сжатия, сохраняет твердый остаток от своей первоначальной длины.

Диапазон II $\left(V_{h t} \leq V_{0}<V_{p}\right)$ : ударник имеет тройную структуру деформирования: гидродинамическое срабатывание+пластическое деформирование+твердый остаток.

Диапазон III $\left(V_{p} \leq V_{0}<V_{s h t}\right)$ : ударник деформируется в двух режимах - гидродинамическое срабатывание + полное пластическое деформирование.

Диапазон IV $\left(V_{0} \geq V_{s h t}\right)$ : ударник полностью срабатывается гидродинамически.

Полное пластическое сжатие либо гидродинамическое срабатывание реализуются только при скоростях III и IV диапазонов.

В случае стационарности коэффициента деформирования $K_{p}$ глубину окончания деформирования в пластической стадии можно оценить как

$$
H=K_{p} \cdot \Delta L_{p},
$$

а в случае стационарности коэффициента относительного проникания $K$ глубину полного срабатывания (глубина проникания в гидродинамическом режиме) можно оценить как

$$
H=K \cdot \Delta L
$$

На рис. 10-12 приведены графики расчета по УМГТ глубины окончания деформирования ударников из трех исследованных материалов (текущая скорость $V>V_{*}$ ) при проникании в песок с параметрами из табл. 5. Экспериментальный коэффициент относительного проникания (в случае стационарности) определяет безразмерную полную глубину проникания в гидродинамическом режиме. В случае медного ударника при $V_{h t}>V_{0} \geq V_{p}$ экспериментальный коэффициент деформирования $K_{p}$ может определять глубину окончания деформирования (но не полную глубину проникания) для пластической стадии проникания. Расчетный коэффициент деформирования $K_{p}$ медного ударника (см. рис. 5 [4]) с учетом торможения стержня по глубине проникания будет уменьшаться (даже при $V \geq V_{p}$ в пределах 5-7\%) и соответственно расчетная глубина окончания деформирования будет несколько меньше значения экспериментального $K_{p}$. 
Таблица 5. Значения характерных скоростей проникания ударников в песок

\begin{tabular}{|c|c|c|c|c|}
\hline Материал ударника, параметры грунта & $\begin{array}{c}V_{*}, \mathrm{~km} / \mathrm{s} \\
\text { (эксперимент) }\end{array}$ & $V_{p}, \mathrm{~km} / \mathrm{s}$ & $\begin{array}{c}V_{h t}, \mathrm{~km} / \mathrm{s} \\
\text { формула (5) }\end{array}$ & $V_{s h t}, \mathrm{~km} / \mathrm{s}$ \\
\hline Медь М1 $\left(\rho_{t}=1.7 \mathrm{~g} / \mathrm{cm}^{3}, C_{x}=1.5, Y_{*}=0.320 \mathrm{GPa}, k=0.13\right)$ & 0.500 & 0.850 & 1.530 & 2.100 \\
\hline Сплав ВНЖ $\left(\rho_{t}=1.7 \mathrm{~g} / \mathrm{cm}^{3}, C_{x}=1.75, Y_{*}=1.775 \mathrm{GPa}, k=0.25\right)$ & 1.092 & 2.500 & 1.930 & 3.400 \\
\hline Сталь 30ХГСА $\left(\rho_{t}=1.8 \mathrm{~g} / \mathrm{cm}^{3}, C_{x}=1.5, Y_{*}=1.34 \mathrm{GPa}, k=0.175\right)$ & 0.996 & 2.550 & 1.980 & 3.500 \\
\hline
\end{tabular}

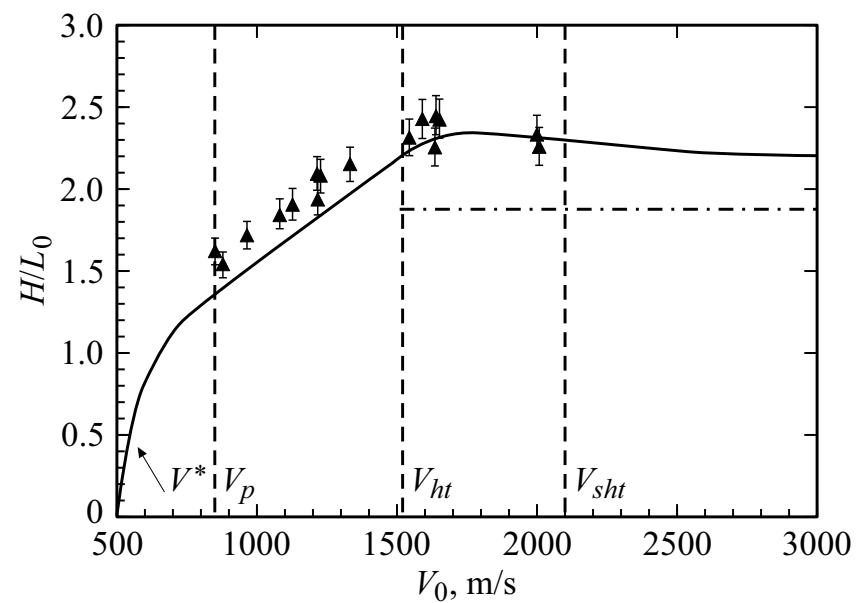

Рис. 10. Глубина окончания деформирования ударника из меди М1 при проникании в песок [4]. - - расчет по УМГТ $\left(\rho_{t}=1.7 \mathrm{~g} / \mathrm{cm}^{3}, C_{x}=1.5\right) ; \boldsymbol{\Delta}-$ эксперимент (табл. 1 , разброс $\pm 5 \%$ ); $-\cdot-\cdot-$ - оценка по формуле М.А. Лаврентьева (17).

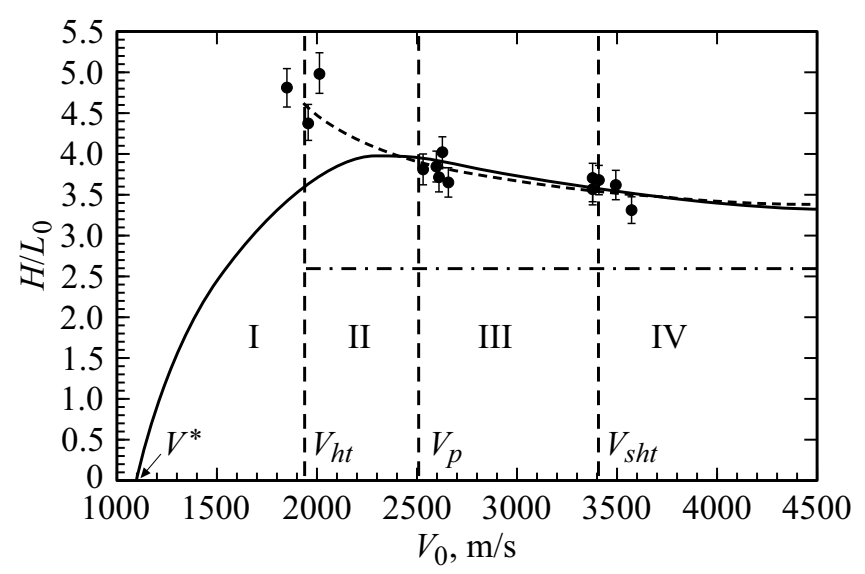

Рис. 11. Глубина окончания деформирования ударника из сплава ВНЖ при проникании в песок: пунктир - формула $(12) ;--$ расчет по УМГТ $\left(\rho_{t}=1.7 \mathrm{~g} / \mathrm{cm}^{3}, C_{x}=1.75\right) ; \bullet-$ эксперимент (табл. 3 , разброс $\pm 5 \%) ;-\cdot-\cdot-$ - оценка по формуле М.А. Лаврентьева (21).

Вертикальными пунктирными линиями на графиках рис. 10-12 обозначены скорости границ четырех диапазонов (табл. 5): скорость гидродинамического пере- хода $V_{h t}$, минимальная скорость полного пластического сжатия $V_{p}$ и минимальная скорость полного гидродинамического срабатывания $V_{s h t}$. На графиках также отмечена критическая скорость $V_{*}$. Горизонтальные штрихпунктирные линии на графиках соответствуют гидродинамическому коэффициенту М.А. Лаврентьева с учетом коэффициента сопротивления $C_{x}$ (значения приведены в табл. 5):

$$
K=\sqrt{\rho_{p} /\left(\rho_{t} C_{x}\right)} .
$$

Для сплава ВНЖ и стали 30ХГСА экспериментальные значения коэффициента относительного проникания $K$, соответствующие пластическому режиму деформирования ударника (левее границы гидродинамического перехода), не могут определять глубину окончания деформирования (тем более полную глубину проникания). Для этих скоростей внедрения $\left(V_{0}<V_{h t}\right)$ глубину окончания деформирования определяет коэффициент деформирования $K_{p}$ (формула $(6)$ ), который меньше $K$ (в случае пластичных металлов - существенно меньше), но в экспериментах с ударниками из сплава ВНЖ и стали 30ХГСА он не определялся. Как было показано выше, только при скоростях внедрения $V_{0} \geq V_{p}$ можно надежно говорить о стационарности обоих коэффициентов $K$ и $K_{p}$ (максимальное изменение по всей глубине не превышает 5\%).

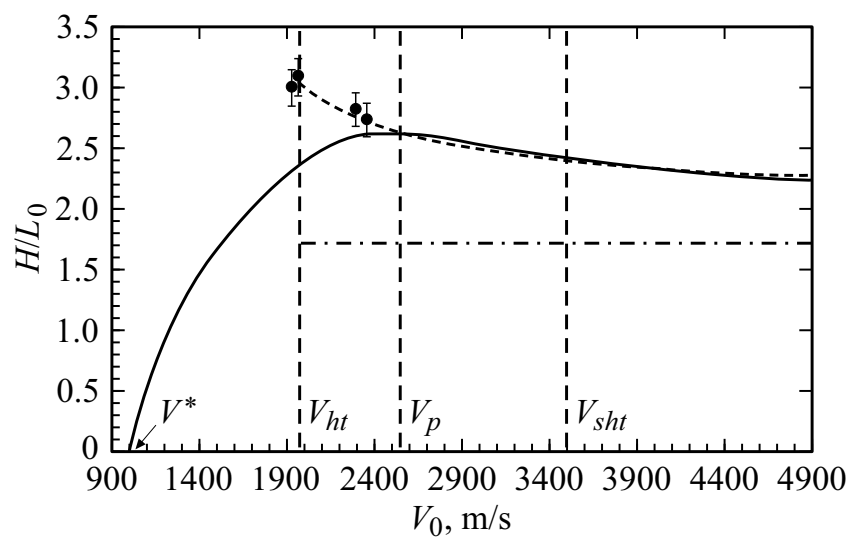

Рис. 12. Глубина окончания деформирования ударника из стали 30ХГСА при проникании в песок. Пунктир - формула $(12) ;-$ - расчет по УМГТ $\left(\rho_{t}=1.8 \mathrm{~g} / \mathrm{cm}^{3}, C_{x}=1.5\right)$, - - эксперимент (табл. 2, разброс $\pm 5 \%) ;-\cdot-\cdot--$ оценка по формуле М.А. Лаврентьева (21). 


\section{6. Эмпирическая формула коэффициента относительного проникания}

Зависимость коэффициента относительного проникания от безразмерной начальной скорости $\tilde{V}=V_{0} / V_{*}$ может быть описана одной относительно простой эмпирической зависимостью

$$
K(\tilde{V})=\frac{1}{\mu} \sqrt{\frac{1}{b}}\left[1+\frac{1}{\sqrt{\tilde{V}^{2}-1}}\right]
$$

вид которой может быть получен из разложения подынтегрального выражения формулы (13) при $V_{0} \rightarrow V_{*}$ : в пределе можно считать, что $U_{0}=V_{0}$ и принять, что коэффициент упрочнения $k=0$, тогда

$$
\sqrt{\frac{1}{1-\frac{2 Y_{p}\left(V_{0}\right)}{C_{x} \rho_{t} U_{0}^{2}}}}=\sqrt{\frac{1}{1-\frac{2 \cdot 0 . S_{x} C_{x} \rho_{t} V_{x}^{2}}{C_{x} \rho_{t} V_{0}^{2}}}} \rightarrow\left[1+\frac{1}{\sqrt{\tilde{V}^{2}-1}}\right] .
$$

На рис. 13 представлены экспериментальные значения коэффициента относительного проникания $K$, умноженного на величину $\mu=\sqrt{\rho_{t} / \rho_{p}}$, в зависимости от $\tilde{V}=V_{0} / V_{*}$, в сравнении с аппроксимацией вида (23).

При аппроксимации экспериментальных данных, соответствующих режиму гидродинамического срабатывания ударника, получаем значение параметра $b=1.5 \pm 0.025$. Для медного ударника использовались экспериментальные данные, соответствующие скорости внедрения $V>V_{p}(\tilde{V}=1.7)$, так как при этой скорости коэффициент относительного проникания можно считать стационарным. Значение параметра $b$ равно среднему коэффициенту сопротивления ударника с плоским передним торцом при проникании в песчаный грунт средней плотности $\rho_{t}=1.7 \mathrm{~g} / \mathrm{cm}^{3}$ и влажности $W=10 \%$,

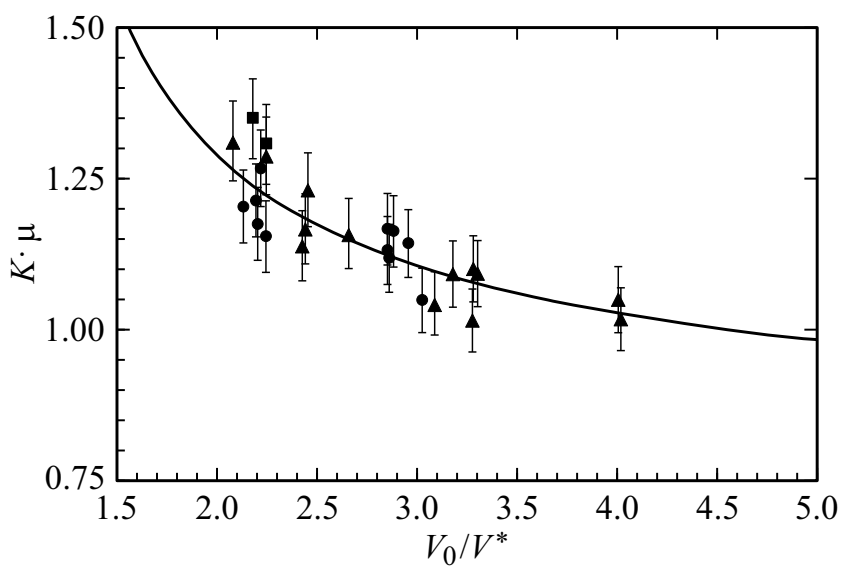

Рис. 13. Нормированный коэффициент относительного проникания. - - формула (22) $\left(\mu=\sqrt{\rho_{t} / \rho_{p}}\right) ; \bullet-$ эксперимент: ударник из сплава ВНЖ (табл. 3 , разброс $\pm 5 \%$ ); $\mathbf{\Delta}-$ эксперимент, ударник из меди М1 (табл. 1, разброс $\pm 5 \%$ ); - - эксперимент, ударник из стали 30ХГСА (табл. 2, разброс $\pm 5 \%)$. который использовался в большинстве наших опытов. Аппроксимирующая кривая на графике (рис. 13) является функцией (18) с $b=C_{x}=1.5$.

\section{Выводы}

Результаты расчетов по усовершенствованной модифицированной гидродинамической теории Алексеевского-Тейта (УМГТ) находятся в хорошем соответствии с опытными данными, полученными при высокоскоростном проникании (скорость удара $V_{0}$ от 0.5 до $3.5 \mathrm{~km} / \mathrm{s}$ ) в песчаный грунт ударников, изготовленных из трех разных металлов: меди М1, сплава ВНЖ и стали 30ХГСА.

С помощью УМГТ и с использованием экспериментальных данных по зависимости коэффициента относительного проникания $K$ (отношение глубины проникания к длине сработавшейся части ударника) от скорости внедрения можно определить коэффициент упрочнения $k$ в линейной зависимости предела текучести материала ударника от реализующегося давления.

При проникании в режиме гидродинамического срабатывания ударника коэффициент относительного проникания $K$ может быть аппроксимирован зависимостью только от отношения начальной скорости внедрения к критической скорости, при превышении которой проникание происходит с пластическим деформированием ударника. Значение критической скорости для конкретных значений плотности материала ударника, плотности и влажности песчаного грунта может отличаться.

\section{Конфликт интересов}

Авторы заявляют, что у них нет конфликта интересов.

\section{Список литературы}

[1] М.В. Каминский, Г.Ф. Копытов, В.А. Могилев, Ю.Ф. Травов, Ю.И. Файков. ПМТФ, 51 (3), 32 (2010).

[2] В.П. Алексеевский. ФГВ, 2,99 (1966).

[3] А. Тейт. Сб. переводов „Механика“, 5, 125 (1968).

[4] A. Tate. J. Mech. Phys. Solids., 17 (3), 141 (1969).

[5] Г.Ф. Копытов, В.А. Могилев, А.П. Снопков. Изв. РАН, 4 (49), 31 (2006).

[6] A. Tate. Int. J. Mech. Sci., 19 (2), 121 (1977).

[7] R.F. Recht. Int. J. Enging. Sci., 16, 809 (1978).

[8] A. Tate. Int. J. Mech. Sci., 28 (9), 599 (1986).

[9] С.И. Герасимов, Д.В. Захаров, А.В. Зубанков, В.А. Кикеев, Е.С. Хорошайло. Научная визуализация, 10 (2), 1 (2018). DOI: $10.26583 /$ sv.10.2.10

[10] В.А. Бердников, М.В. Каминский, Ю.Г. Киселев, Г.Ф. Копытов, В.А. Могилев, Ю.Ф. Травов, Ю.И. Файков, Ю.А. Фатеев. Экспериментальное исследование движения конусов и цилиндра в песчаной среде. Сборник материалов ІІ-ой научной конференции РАРАН „Современные методы проектирования и отработки ракетноартиллерийского вооружения“. (РФЯЦ-ВНИИЭФ, Саров, 2002), с. $276-279$. 
[11] Ю.В. Батьков, Б.Л. Глушак, С.А. Новиков. ФГВ, 25 (5), 126 (1989).

[12] Л.П. Орленко (ред.). Физика взрыва (Физматлит, М., 2004), т. 2.

[13] М.А. Лаврентьев. УМН, 4, 41 (1957).

[14] С.И. Герасимов, В.И. Ерофеев, Ю.Ф. Травов, А.Г. Иоилев, В.В. Писецкий, А.П. Калмыков, С.А. Капинос, Н.В. Лапичев. ЖТФ, 91 (3), 542 (2021). DOI: $10.21883 /$ JTF.2021.03.50535.233-20

[15] С.И. Герасимов, В.И. Ерофеев, Е.Г. Косяк, В.А. Кикеев, В.В. Писецкий. ЖТФ, 90 (8), 1374 (2020). DOI: $10.21883 /$ JTF.2020.08.49550.365-19

[16] С.И. Герасимов, В.И. Ерофеев, А.В. Зубанков, В.А. Кикеев, В.В. Писецкий. ИФЖ, 94 (1), 174 (2021).

[17] И.С. Григорьев, Е.З. Мейлихов (ред.). Физические величины, справочник. (Энергоатомиздат, М., 1991) 